\title{
Welcome to Economies in IS!
}

\author{
On the Plethora of IT-Enabled Economies
}

\author{
Christof Weinhardt $\cdot$ Christian Peukert • Oliver Hinz $\cdot$ Wil M. P. van der Aalst
}

Published online: 6 July 2021

(C) The Author(s) 2021

\section{The Rise of Economies}

With the proliferation of IT, the fate of the old economy was sealed, and the beginning of the new economy was marked. The new economy focuses on providing services rather than on optimizing the industrial production of goods. The exchange of information and software plays a key role in the new economy. For a long time, these two economies coexisted, but the influence of the new economy has become stronger and stronger so that some traditional business models have become obsolete and have finally been replaced by novel ones. Essentially, there has been a shift from a heavy industry economy to a more (information) technology-driven economy. Yet, the development of the new economy was by no means straightforward and uneventful, as illustrated by the burst of the dot-com bubble, frequently referred to as the crisis of the new economy (Buhl and Jetter 2009). Today, it is not that the

\section{Weinhardt $(\square) \cdot$ C. Peukert}

Institute of Information Systems and Marketing (IISM),

Karlsruhe Institute of Technology (KIT), Kaiserstr. 89-93,

76133 Karlsruhe, Germany

e-mail:weinhardt@kit.edu

C. Peukert

e-mail: christian.peukert@kit.edu

\section{O. Hinz}

Faculty of Economics and Business Administration, Goethe University Frankfurt, Theodor-W.-Adorno-Platz 4,

60323 Frankfurt am Main, Germany

e-mail: ohinz@wiwi.uni-frankfurt.de

W. M. P. van der Aalst

RWTH Aachen, Lehrstuhl Für Informatik 9, Ahornstr. 55, 52056 Aachen, Germany

e-mail: wvdaalst@pads.rwth-aachen.de old economy is dead - some traditional companies are still quite successful players, but very often struggle with changes necessary for sustainable business models. Meanwhile, however, a new development is taking place on the side of the new economy: Researchers and business practitioners are recognizing a multitude of novel (sub-)economies or subsectors of the new economy: Digital economy, sharing economy, platform economy, gig economy, token economy, just to name a few. ${ }^{1}$ These economies have the potential to - or already have revolutionize(d) the way individuals, groups, enterprises, and society participate in or run business activities. While some of them already possess a remarkable age [e.g., Shapiro and Varian (1998) coined the term network and information economy more than 20 years ago], others have only recently started to attract wide attention [e.g., the token economy (Sunyaev et al. 2021)]. However, the fact is that some companies acting under the umbrella of these economies have developed into massive economic players today. Some examples:

- Gig economy: Uber, Lieferando, Deliveroo, Uber Eats, Amazon Mechanical Turk, etc.;

- Sharing economy: Airbnb, Stashbee, BlablaCar, Lime, Couchsurfing, etc.;

- Platform economy: Amazon, Zalando, Bol, Alibaba, eBay, etc. (van der Aalst et al. 2019).

When one browses the track descriptions of this year's ICIS conference, four different economies are particularly named (i.e., circular economy, sharing economy, gig

\footnotetext{
${ }^{1}$ The individual economies are not necessarily disjunct and can sometimes be seen as subsets of each other. Furthermore, terms are used synonymously in literature, e.g., some refer to the new economy also as digital, information, or network economy.
} 
economy, and crowd economy). Similarly, across all BISE articles originating from the last two years (since 2019), ten different types of economies have been denoted. These comprise (number of different articles mentioned): Platform economy (5), digital economy (6), sharing economy (6), circular economy (1), token economy (2), DLT (distributed ledger technology) economy (1), internet economy (1), gig economy (2), OTF (on-the-fly computing) economy (1), and attention economy (1).

As different as they may appear, they all have in common that they either create new business models by leveraging technological innovations (e.g., blockchain, artificial intelligence, etc.) or are the consequence of these innovations. Therefore, the rise of these economies is highly relevant for BISE authors and readers. Research on some of these economies is deeply rooted in the IS discipline, whereas others may only play a much more prominent role in the future. Due to the plethora of economies that have emerged in recent years, we have seen the need to provide an overarching structure, but also to critically question whether the existence of this multitude of economies is justified.

\section{Structuring Economies}

While some of these economies solely rely on technological factors, i.e., technical innovations, in describing their unique selling proposition, others draw on business model innovations (mechanism focus) or highlight socio-technical consequences (consequence focus). To put the prior mentioned categories into context: Economies with a technology focus can be understood as driving forces for economies with a mechanism focus that make use of technology to enable certain functionalities (e.g., connecting peers) or for economies with consequence focus. The latter refers to a resulting phenomenon that can be ascribed to the use of technologies or the application of technologydriven business models. However, economies with a consequence focus do not necessarily result from economies with a mechanism focus and can also emerge directly from an economy with a technology focus. Figure 1 presents an exemplary assignment of different economies to the three categories technology focus, mechanism focus, and consequence focus, thereby also outlining the potential relationships between the categories. For the sake of simplicity, we will not elaborate on possible dependencies within the individual categories and will only list some exemplary economies that could be assigned to the various categories.

- Technology focus. This category centers on technological factors. Exemplary economies are the digital economy, token economy (Sunyaev et al. 2021), blockchain economy (Beck et al. 2018), platform economy (Dann et al. 2021; van der Aalst et al. 2019), internet economy (Buxmann and Hinz 2013), network economy/information economy (Shapiro and Varian, 1998), or API economy (Schlauderer and Overhage 2018).

- Mechanism focus. This category primarily emphasizes the mechanisms and ways of how business is conducted. Exemplary economies are the sharing economy (Puschmann and Alt 2016), gig economy (Huang et al. 2020), e-lance economy (Malone and Laubacher, 1999), circular economy (Hawlitschek 2021), or crowd economy (ICIS 2021 track descriptions).

- Consequence focus. The category sheds light on sociotechnical consequences. Exemplary economies are the reputation economy (Nuremberg Institute for Market Decisions 2020), attention economy (Hinz et al. 2020), surveillance economy (Peukert et al. 2018), experience economy (Jung et al. 2016), or access economy (Tan et al. 2017).

The following example serves to illustrate a chain of effects between different categories: The platform economy (driving force) facilitates the realization of the sharing economy by offering a platform infrastructure that enables the mediation between individual peers (functionality). Again, a dependency can be derived between the sharing economy and the reputation economy. Since trust, and with it also reputation, is the fundamental prerequisite for transactions in the sharing economy, the reputation economy is a phenomenon that has partly emerged as a consequence of the sharing economy.

\section{Who will be the Next Shooting Star in the IS Discipline?}

In a previous editorial, we discussed the attention economy with reference to attention directed from research peers to a steadily increasing number of new research pieces and directions (Hinz et al. 2020). As the diversification of economies seems to increase steadily, a hyper-fragmentation of IS research might occur and a similar problem may soon arise here. Thus, from an IS research perspective, the question pops up as to which economy to focus attention on best. Let us highlight two economies that may play a major role in the future:

Circular Economy. While the circular economy is firmly established in the research repertoire of other disciplines (e.g., production science), the IS discipline has, so far, been rather cautious about conducting extant research in this 


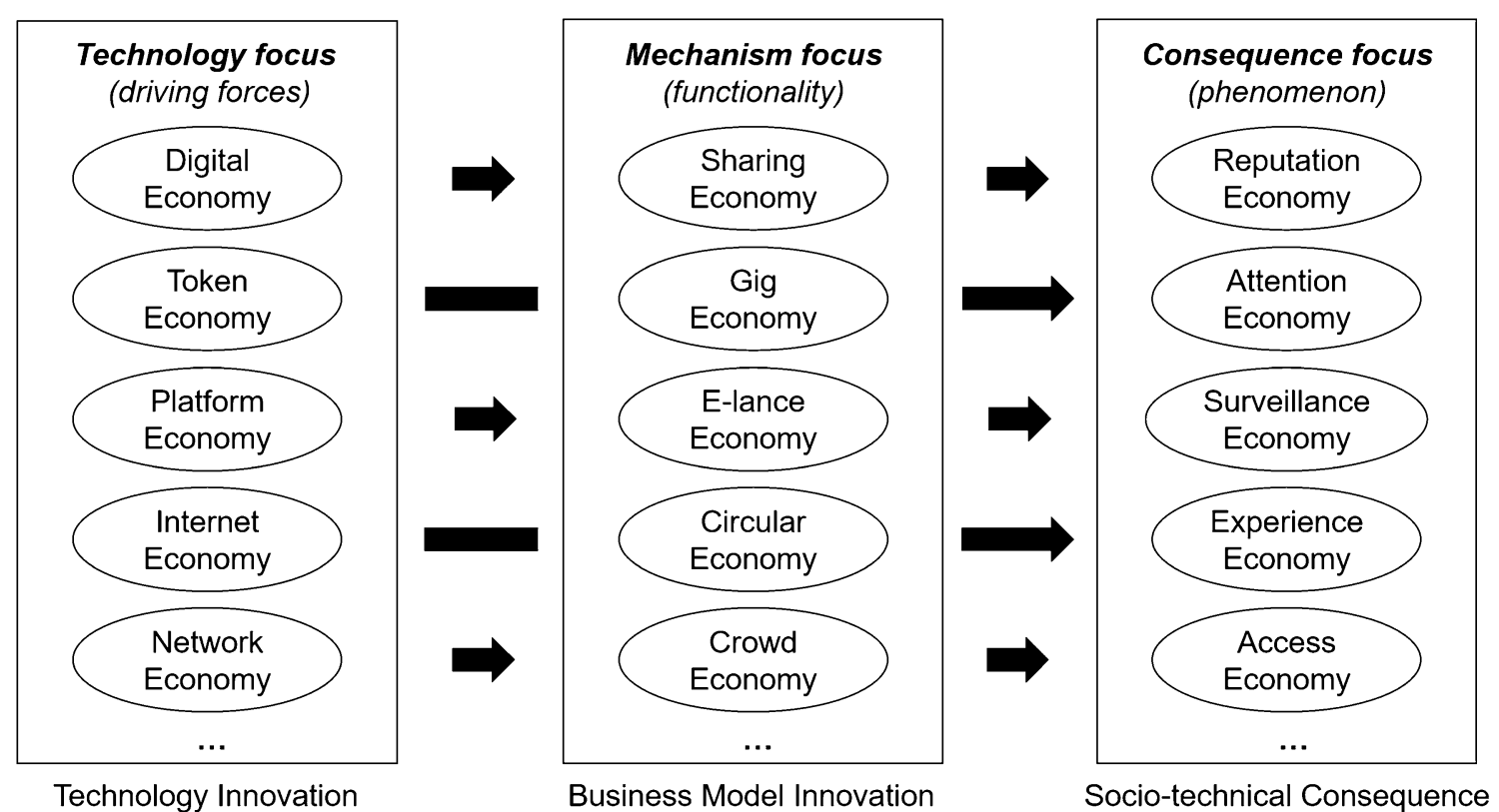

Fig. 1 Classification of the economies into the categories of technology focus, mechanism focus, and consequence focus

area. However, due to the growing importance of sustainability, it is essential to elaborate on the IS discipline's role within the circular economy. Since the circular economy relies on extensive IT-based connectivity and traceability, there are several potential avenues in which the IS discipline can contribute with its competencies. The integrated acquisition, secure processing, and timely provision of information on the condition of components and products throughout the entire product lifecycle thereby provides a fundamental challenge for companies and regulatory authorities - issues for which the IS discipline is well equipped with its methods and tools.

\footnotetext{
Algorithm Economy. In 2015, Gartner introduced the idea of the algorithm economy and proclaimed a similar evolution for algorithms as we witnessed with apps (Sondergaard 2015). Marketplaces, on which the primary goods to sell and buy are algorithms, will be instantiated offering various algorithms to solve diverse tasks. Thus, products are no longer differentiated by the underlying hardware, but primarily by the algorithms that run behind the scenes. In the same vein, Kowalkiewicz (2019) outlines the idea of the Economy of Algorithms in which algorithms act as economic agents that are hired by individuals to act on their behalf (thus shifting, e.g., from B2C to B2A(lgorithm)2C transactions). Thereby, Kowalkiewicz (2019) postulates that the rise of the economy of algorithms is attributed to advancements in the area of the Internet of Things, the algorithms themselves, and appropriate business models - all areas that fall into the scope of BISE research.
}

Particularly the BISE Catchword section provides a unique opportunity to introduce, define, and raise awareness of new economies for the BISE community, thereby outlining the significance for and potential contributions of the IS discipline. Speaking of the Catchword section, we would also like to take this opportunity to thank Ulrich Frank (University Duisburg/Essen, Germany) for his great work for the BISE Catchword section and to warmly welcome Christine Legner (HEC, University Lausanne, Switzerland) as his successor.

\section{Relevance for BISE and Remaining Questions}

The IS discipline has made and continues to make important contributions to the understanding of emerging economies (e.g., sharing and platform economy). However, besides the exploration of novel economies or the more profound investigation of already existing ones, the linkage and study of interrelations between economies is also an interesting direction for future BISE research. Initial ideas have already been followed, such as addressing the essential precondition of trust in the sharing economy through blockchain technology, hence linking facets of the sharing economy with the blockchain economy (Hawlitschek et al. 2018).

Furthermore, the fundamental question must be asked as to whether the different economies have a right to coexist or whether they pursue similar goals, i.e., do we need all these economies? Consequently, interrelationships and differences between economies should be pointed out to 
avoid a hyper-fragmentation of our research work, e.g., repeated research that captures the same phenomena over and over again, i.e., do we need to conduct research again and again for each economy? Therefore, hypes around new buzzwords and sometimes the introduction of novel economies based on them should be well-justified and delineated from existing ones with care.

In the future, we need to carefully select and motivate the economies on which the focus shall be directed. As most economies have evolved in the context of digital transformation and advances in IT-related innovations, the demand for our community's expertise is greater than ever before in order to evaluate the importance and to study the consequences of these rising economies for business and society.

Funding Open Access funding enabled and organized by Projekt DEAL.

Open Access This article is licensed under a Creative Commons Attribution 4.0 International License, which permits use, sharing, adaptation, distribution and reproduction in any medium or format, as long as you give appropriate credit to the original author(s) and the source, provide a link to the Creative Commons licence, and indicate if changes were made. The images or other third party material in this article are included in the article's Creative Commons licence, unless indicated otherwise in a credit line to the material. If material is not included in the article's Creative Commons licence and your intended use is not permitted by statutory regulation or exceeds the permitted use, you will need to obtain permission directly from the copyright holder. To view a copy of this licence, visit http://creativecommons. org/licenses/by/4.0/.

\section{References}

Beck R, Müller-Bloch C, King JL (2018) Governance in the blockchain economy: a framework and research agenda. J Assoc Inf Syst 19(10):1020-1034

Buhl HU, Jetter M (2009) BISE's responsibility for our planet. Bus Inf Syst Eng 1(4):273-276

Buxmann P, Hinz O (2013) Makers. Bus Inf Syst Eng 5(5):357-360
Dann D, Teubner T, Wattal S (2021) Call for papers, issue 5/2022platform economy: beyond the traveled paths. Bus Inf Syst Eng 63(2):213-214

Hawlitschek F (2021) Interview with Benjamin Scheffler on "the future of waste management". Bus Inf Syst Eng 63(2):207-211

Hawlitschek F, Benedikt N, Timm T (2018) The limits of trust-free systems: a literature review on blockchain technology and trust in the sharing economy. Electron Commer Res Appl 29:50-63

Hinz O, van der Aalst WMP, Weinhardt C (2020) Research in the attention economy. Bus Inf Syst Eng 62(2):83-85

Huang N, Burtch G, Hong Y, Pavlou PA (2020) Unemployment and worker participation in the gig economy: evidence from an online labor market. Inf Syst Res 31(2):431-448

Jung T, tom Dieck MC, Lee H, Chung N (2016) Effects of virtual reality and augmented reality on visitor experiences in museum. In: Inversini A, Schegg R (eds) Information and communication technologies in tourism 2016. Springer, Cham, pp 621-635

Kowalkiewicz M (2019) Why you should care about the rising economy of algorithms. https://towardsdatascience.com/whyyou-should-care-about-the-rising-economy-of-algorithmscb33959acfe0. Accessed 1 May 2021

Malone TW, Laubacher RJ (1999) The dawn of the e-lance economy. In: Nüttgens M, Scheer A (eds) Electronic business engineering. Springer, Heidelberg

Nuremberg Institute for Market Decisions (2020) The reputation economy. NIM Mark Intell Rev 12(2):1-66

Peukert C, Adam MTP, Hawlitschek F, Helming S, Lux E, Teubner T (2018) Knowing me, knowing you: biosignals and trust in the surveillance economy. In: Proceedings of the 39th international conference on information systems (ICIS), pp 1-9

Puschmann T, Alt R (2016) Sharing economy . Bus Inf Syst Eng 58(1):93-99

Schlauderer S, Overhage S (2018) BoSDL: an approach to describe the business logic of software services in domain-specific terms. Bus Inf Syst Eng 60(5):393-413

Shapiro C, Varian HR (1998) Information rules: a strategic guide to the network economy. Harvard Business School Press, Boston

Sondergaard P (2015) Wake up to the algorithm economy. https:// www.gartner.com/smarterwithgartner/wake-up-to-the-algo rithm-economy/. Accessed 1 May 2021

Sunyaev A, Kannengießer N, Beck R, Treiblmaier H, Lacity M, Kranz J, Fridgen G, Spankowski U, Luckow A (2021) Token economy. Bus Inf Syst Eng 63(4) (in press)

Tan FTC, Tan B, Lu A, Land L (2017) Delivering disruption in an emergent access economy: a case study of an e-hailing platform. Commun Assoc Inf Syst 41(1):497-516

van der Aalst W, Hinz O, Weinhardt C (2019) Big digital platforms: growth, impact, and challenges. Bus Inf Syst Eng 61(6):645-648 